\title{
Tuberculosis en niños
}

\author{
Dra. Daysi Lewinson X. '; Dra. Nadirne Clerc F. ${ }^{1}$; Dr. Leonardo Vejar $\mathbf{M .}^{2}$
}

\section{Child tuberculosis in southeast Santiago}

Twenty two cases of tuberculosis (TB) in children along 1985 at south-east Santiago were retrospectivelly analized. There were 4 cases of extrapulmonary primary locations: 2 renal and 2 meningeal TB. All four patient had scars of previous BCG vaccination. Thirteen asymptomatic paticnts were detected at screening procectures for contacts of active TB cases. In 7 of 18 cases with lung TB tubetcle bacilli was isolated from sputum or gastric aspirate. In 5 of 17 cases of lung TB chest films including three patients with positive cultures for tubercle bacilli and other two that were diagnosed by positive P.P.D. (2 U) reactions. Treatment was done in accordance to national recomendations and all patients responded to it. Only one casc of meningeal TB show mild neurological sequelae. (Key words: tuberculosis, children, contacts, diagnosis.)

La tuberculosis (TBC) sigue constituyendo un problema de salud pública, aunque las cifras de morbimortalidad, por la enfermedad en nuestro país, muestran disminución importante de las tasas, especialmente de mortalidad, que de alrededor de 250 por cien mil habitantes al comienzo del siglo han disminuido a 7,4 por cien mil en $1984^{i-3}$. Este descenso se ha concentrado principalmente en los menores de 15 años cuya mortalidad disminuyó de $1,9 \times 100$ mil en 1974 a $0,5 \times 100$ mil en $1984^{1,3,4}$, lo que es atribuible al desarrollo activo de progra. mas antituberculosos, nuevos esquemas terapéuticos y generalización de medidas preventivas como vacunación masiva $\mathrm{BCG}$, que actualmente alcanza coberturas superiores a $90 \%$ en menores de 14 afros ${ }^{5,6}$.

Esta revisión tiene como propósito describir el estado actual de la TBC infantil en un área urbana pobre de Santiago y analizar los criterios de diagnóstico de la enfemredad.

\section{MATERLAL Y METODO}

Se incluyeron en el estudio Ios 22 pacientes que corresponden a todos los casos de TBC en menores de

1. Médico del Servicio de Pediatria, Unidad Broncopulmonar. Hospital Sótero det Río (S.S.M.S.O.).

2. Jefe de Unidad Broncopulmonar, Servicio de Pediatría. Hospital Sótero del Río (S.S.M.S.O.).
15 años detectados en el área suroriente de Santiago en el período comprendido entre el $1^{\circ}$ de encto do 1985 y el 31 de diciembre de 1985 .

Lin cada caso se rezistró edad, sexo, estado de nutrición (según NCHS), tipo de pesquisa (contacto o sintomático), rclación con el caso índice, antecedentes de vacunación $\mathrm{BCG}$, reacción de PPD (se considcraron positivos a las de $6 \mathrm{~mm}$ o más en menores de 6 atos y de $8 \mathrm{~mm}$ o más en niños mayores). Las tadiografías de tórax $y$ el resultado del estudio para bacilo de Koch fueron clasificadas según las normas nacionales de enrermedades respiratorias ${ }^{7}$.

Los exámenes bacteriológicos fueron realizados de preferencia en expectoración y, cuando esto no fue posible (lactantes o falta de cooperación), en muestras de contenido gástrico. En las TBC extrapulmonares el estudio de Koch se realizó según su ubicación (orina, LCR). También se analizó la cxistencia de alguna enfermedad concomitante.

Todos los pacientes fueron tratados según las normas nacionales de manejo de TBC infantil ${ }^{7}$.

\section{RESULTADOS}

Siete pacientes eran hombres y 15 mujeres, 2 eran menores de 2 años, 6 tenían entre 2 y 6 aflos y 14 más de 6 y hasta 15 años. La información del estado de nutrición se obtuvo en 18 niños, 12 eran eutróficos, 5 desnutridos y uno obeso.

Nueve pacientes consultaron por sintomas de enfermedad tuberculosa, entre ellos, 2 meningitis TBC y 2 infecciones renales. Los 13 restantes fueron pesquisados por antecedentes de contactos con otro paciente tuberculoso conocido. El 
tipo de contacto fue conocido en 17 pacientes: su madre era la fuente de contacto en 11 .

Se confirmó que la vacunación BCG se había realizado en 15 pacientes, uno no tenía cicatriz de vacuna y el dato no se constató en los 6 pacientes restantes.

La ubicación de la TBC de los 22 casos correspondió en 18 pacientes a TBC pulmonar, 2 a TBC renal y 2 a TBC meningea. En la tabla 1 se consigna la localización de la tuberculosis y la existencja de vacunación con BCG en cada forma clínica.

Los 2 niños con TBC renal tenian cicatriz BCG. De los 2 niños con IBC meníngea uno era un preescolar que había sido vacunado recién nacido y el otro un escolar con reacción por vacuna BCG reciente, supurada, administrada por primera vez después de detectar en su padre TBC bacilifera.

De 14 niños vacunados, 9 tenian reacción positiva al PPD, 2 negativa, y en 3 no se registró dicha reacción. En dos niños no vacunados resultó positiva. En los 6 casos restantes la información registrada era insuficiente para establecer relaciones.

Las radiografias de tórax fueron informadas como normales en 5 niños, 9 tenían lesiones mínimas y 3 moderadas. En 5 casos no fue posible recuperarlas.

El estudio de Koch en las muestras de contenido gástrico dio resultados positivos en el cultivo de 5 niños en que se realizó. Cuando se buscó el bacilo de Koch en expectoraciones, los resultados fueron positivos en 6 cultivos de 13 niños y en un examen directo; sólo en un paciente se obtuvieron resultados positivos del estudio directo y del cultivo.

Los dos casos de tuberculosis meningea fueron confirmados por cultivo de LCR. De los dos niños con TBC renal, en uno la baciloscopia

Tabla 1

Vacuna BCG y localización de la enfermedad en 22 nuîos con tuberculosis

\begin{tabular}{lrccr}
\hline BCG & $\begin{array}{c}\text { TBC } \\
\text { pulmonar }\end{array}$ & $\begin{array}{c}\text { TBC } \\
\text { renal }\end{array}$ & $\begin{array}{c}\text { TBC } \\
\text { meningea }\end{array}$ & Total \\
\hline Sí & 11 & 2 & 2 & 15 \\
No & 1 & 0 & 0 & 1 \\
No consignado & 6 & 0 & 0 & 6 \\
TOTAL & 18 & 2 & 2 & 22 \\
\hline
\end{tabular}

TBC $=$ Tuberculosis. directa y el cultivo, y en el otro, sólo la baciloscopia directa resultaron positivos en las respectivas muestras de orina.

Al correlacionar el resultado de la radiografía de tórax con el estudio bacteriológico en los niños con TBC pulmonar, encontramos que de los 12 niños con lesiones pulmonares radioló. gicamente demostrables, en sólo cuatro se aistó el bacilo de Koch, uno tenía, además, baciloscopia directa positiva. En tres pacientes con radiografía de tórax normal los estudios de Koch en expectoración o contenido gástrico dieron cultivos positivos para B. de Koch.

De los casos de TBC extrapulmonar, en los dos niños con infecciones renales la radiografia de tórax fue normal. En pacientes con TBC meníngea, sólo uno mostraba lesiones y éstas eran mínimas.

Cinco de los 22 niños con TBC sufrían síndrome bronguial obstructivo como enfermedad concomitante; el resto no presentaba evidencia de otras afecciones. Ningún paciente de esta serie falleció.

\section{DISCUSION}

La morbilidad por tuberculosis en nifĩos chilenos va en descenso, camo lo muestran las tasas en años sucesivos, siendo en 1982 de 11,5 por $100 \mathrm{mil}$ niños; en 1983 de 10,9 y en 1984 de $9,2^{3}$. Basándose en nuestra revisión, en el área suroriente de Santiago 1985 la tasa correspondió a $9,9 \%$.

La asociación de tuberculosis y desnutrición es un hecho descrito por otros autores ${ }^{8}$. La proporción de desnutridos entre nuestros pacientes fue de $28 \%$, siendo la del área de salud, en el mismo período, de $16,5 \%$ en menores de 6 años (no se dispone de cifras de desnutrición en escolares). Esta asociación no se debería a aumento del número de infectados: en la tuberculosis existirían factores predisponentes que facilitarian su progresión, como son diversos grados de anergia y otras alteraciones de la inmunidad.

En la pesquisa de la enfermedad destacó el antecedente de contacto con un adulto tuberculoso conocido (13/22). Sólo 9 pacientes $(41 \%)$ consultaron por síntomas de la enfermedad. Esto concuerda con otras publicaciones y por eso hacemos hincapié en la necesidad de continuar el estudio de los contactos. Las madres siguen siendo la principal fuente de contagio 
para los nifios, ya que con ellas se establecen los contactos más directos y prolongados ${ }^{8,9}$.

Otro hecho ya descrito es que la vacuna BCG no excluye la posibilidad de enfermar de ninguna de las localizaciones de $\mathrm{TBC}^{\mathrm{g}, 9}$.

El diagnóstico de $\mathrm{TBC}$ meníngea se confimó en ambos casos con cultivos de líquido cefalorraquídeo positivos. El niño escolar curó sin secuelas; en cambio, el preescolar se controla actual. mente en neurología por trastornos de conducta $y$ aprendizaje.

Parece importante recalcar que el PPD negativo puede ocurrir en enfermos tuberculosos, tanto en niños vacunados o no vacunados. $\mathrm{La}$ desnutrición, un estado inmunitario deficiente o ambos pueden ser responsables de este hecho, que debe ser considerado, pues en estos casos el diagnóstico tendrá fundamentos en otros parámetros clínicos y de laboratorio?. Por otra parte, la reacción positiva al $\mathrm{PPD}$ en enfermos no vacunados apoya fuertemente el diagnóstico e indica infección por bacilo de Koch, pero no necesariamente enfermedad ${ }^{11}$.

Como es habitual, hubo franco predominio de las formas pulmonares de TBC: sin embargo, cada vez aparecen con mayor frecuencia localizaciones extrapulmonares ${ }^{2}$ como ocurrió en nuestra serie. Las TBC extrapulmonares deben estar presentes en las hipótesis de diagnóstico clínico de las diversas especialidades médicas que ya constituyen una proporción cada vez más alta del total de las tuberculosis diagnosticadas.

Las radiografías resultaron orientadoras en 71 \% de los pacientes, siendo francamente predominantes las lesiones mínimas. Las radiografías de tórax normales no excluyen la posibilidad de que exista una forma inaparente de TBC ${ }^{11}$.

El rendimiento de los estudios bacteriológicos en la TBC del niño oscila en las diferentes publicaciones entre el 15 y $40 \%$, francamente menor que en el adulto ( 80 a $90 \%$ ). En nuestro estudio el laboratorio confirmó el diagnóstico en casi la mitad de los casos, lo que demuestra un alto rendimiento del examen, siendo el cultivo de Koch el más importante. Creemos que la búsqueda rutinaria del bacilo de Koch en nirnos sanos o sin. tomáticos respiratorios, en contacto con pacientes tuberculosos, contribuyó a aumentar el número de casos diagnosticados precozmente.

Otto hallazgo importante fueron los cultivos de Koch positivos en pacientes con radiografías de tórax normal (3 niños). Las lesiones radioló- gicas demostrables tuvieron confirmación bacteriológica en $33 \%$ de los casos.

La incidencia de la TBC en niños en nuestra área muestra tendencia al descenso, concordante con lo observado a nivel nacional en los últimos años. La TBC sigue siendo un problema actual; su diagnóstico oportuno depende del estudio de los contactos TBC, de la sospecha clinica y de los esfuerzos que se hacen para confirmarla con los examenes de laboratorio analizados. Ella debe investigarse en los contactos directos sintomáti. cos respiratorios o sanos y en niños con imágenes radiológicas sugerentes o atipicas.

\section{RESUMEN}

Se realizó un análisis retrospectivo de todos los casos de TBC infantil del S.S.M.S.O. de Santiago en el período enero a diciembre de 1985 (22 niños). La tasa fue de $9,9 \%$. Se encontró una alta proporción de localizaciones extrapulmonares ( 2 meníngeas y 2 renales), los 4 pacientes vacunados con BCG. Se revisó el rendimiento de los distintos parámetros diagnósticos destacando la importancia del estudio de contacto. Cinco TBC pulmonares tenían radiografía de tórax normal, basándose el diagnóstico en tres de ellos en bacteriología positiva y en los otros dos por el viraje tuberculínico. Todos se trataron con los esquemas propuestos en normas nacio. nales. No hubo mortalidad en nuestro grupo.

\section{AGRADECIMIENTOS}

Se agradece la colaboración en la revisión del presente trabajo de los doctores Sergio Ibáñez y Gustavo Ross.

\section{REFERENCIAS}

1. Toro J.: Tuberculasis. ¿Problema resuelto? (Edit) Act Méd FAB $1985 ; 8: 47-48$.

2. Valenzuela $P$.: Tuberculosis: actualidad clínica y terapéutica. Act Mèd FAB 1982; $5: 11-17$.

3. Moristerio de Salud: "Manual y Normas de Tuberculosis", Chile 1985.

4. Toro J.: "Manual y Normas de Tuberculosis". Ministerio de Salud $1985 ; 7-12$.

5. Ibáñez S.: TBC Infantil. Enf Resp Cir Torac 1985; 1: 140-145

6. Rojas L.: "Tuberculosis en Chile". Enf Resp Cir Torac 1985; 1: 4-9. 
7. Ministerio de Salud: "Nomas de Pediatría". Enfermedades respitatorias $y$ tuberculosis. Chile, 1981.

8. Véjar 1., Solar E: "Tubcreulosis Pulmonar en cl Lactante". Rer Chil Pediatr 1982; 53: 565-569.

9. Ibánez S., Ross G., Ledesma O., Diaz M.: "Experiencia de 7 años en tuberculosis pulmonar infantil". Revisión de 323 casos hospitalizados en ef periodo 1962-1969. Rew Chil Pediatr 1973; 44 ; 319-323.

10. Lowsky J., Pio A. "El conttol mundial de la tuberculosis es posible". Act Méd FAB 1982; 5: 8-10.

11. Ross $G$.: "Tuberculosis Pulmonar en el Nin̄o". En "Manual de Pediatria", Vol. 1, Winter F.., Puentes R. (Eds) Santiage, Chile, IMC Color, 1984; 269289. 